\title{
Industry 4.0: New Challenges and Opportunities for the Labour Market
}

\author{
Sandrine Kergroach \\ Senior Economist, Centre for Entrepreneurship, SMEs, Local Development and Tourism, Sandrine.Kergroach@oecd.org \\ Organisation for Economic Cooperation and Development, OECD, 2, rue Andre Pascal 75775 Paris Cedex 16, France
}

\begin{abstract}
$\mathrm{T}$ The introductory article to the special issue "Labour Market in the Context of Technological Transformations" presents an overall picture of the latest technological trends altogether referred to as the Fourth Industrial Revolution (Industry 4.0), their impact on the changing structure of the labour market, the demand for

prospective skills, as well as emerging policy challenges. The author concludes that ensuring the resilience, adaptability and efficiency of labour markets are therefore not only a matter of addressing the skills needs of the Next Production Revolution, but also a prerequisite to social stability and cohesion.
\end{abstract}

Keywords: new production revolution; labour market;

Citation: Kergroach S. (2017) Industry 4.0: New Challenges and Opportunities for the Labour Market. Foresight and STI Governance, vol. 11, no 4, pp. 6-8. demand for skills; production automation; social implications DOI: 10.17323/2500-2597.2017.4.6.8

$\mathrm{W}$ e are living on the threshold of the next production revolution. Ongoing transformations in industry and production activities are unprecedented in terms of their scale and impact. Emerging technological developments are likely to bring widespread automation and irreversible shifts in the structure of jobs, raising major challenges on labor markets and for policymakers responsible for promoting the necessary skills and employment.

Labor and technology have long nurtured a close and mutually beneficial relationship [Keynes, 1930]. While technological change has helped improve labor productivity and has been therefore translated at the firm- and macro-levels into economic growth and job creation, new technologies have substituted labor in many industries and occupations, displacing jobs across sectors, regions, or trades. Capitalization effects have benefited the sectors and enterprises in transition, as well as related sectors and partner firms that have captured positive spill-overs through pervasive supply chains. However, at the same time, destructive effects have disproportionately hit industries, territories, and populations that demonstrated a deficit of skills or lag behind the digital transition.

Our world is going through a deep digital transformation. The Internet of Things (IoT), i.e., the connection of all kinds of devices, objects, and sensors via the Internet, is mutating into a gigantic, powerful and hyper-responsive "superorganism" that can monitor, inform, manage operations, and take action in realtime without the active involvement of individuals, furthermore generating an unprecedented volume of data [OECD, 2015a].

Combined with big data analytics and the storage capacity of cloud computing, the IoT can empower new predictive approaches to decision-making, new business models, intelligent systems, and fully autonomous machines [OECD, 2016]. Applications are spreading rapidly with tremendous repercussions to be expected across a large range of sectors. The IoT in particular enables smart manufacturing by providing data and tools for improving factory operations and better managing risk in the supply chain from product logistics to inventory management to machine maintenance. In network industries, IoTenabled smart grids allow for monitoring traffic, emergencies, infrastructure usage, cutting power outages, reducing waste, and implementing smart pricing programs. 
Likewise, artificial intelligence (AI), i.e., the ability of machines and systems to acquire knowledge and carry out cognitive tasks and intelligent behaviors, can empower new kinds of software and robots to learn and operate independently from human decisions and become self-governing agents.

Combined with the advances in mechanical and electrical engineering, AI can expand the capacity of industrial robots to adapt to the physical world and changing working environments with no reprogramming. AI-enabled robots will increasingly be central to logistics and manufacturing as they possess the potential to ensure greater safety, speed, precision, and productivity. Machine learning is also poised to revolutionize a number of services including marketing, finance, entertainment, and medicine. For instance, AI-based algorithms could help anticipate market fluctuations and the automation of health-related tasks, which could increase the autonomous capacity of surgical robots.

3D printing, i.e., additive manufacturing techniques that allow for building products by adding material in layers, is another example of emerging technologies that have a high potential for transforming production processes and supply chains.

Combined with digital technologies, 3D printing will have far-reaching applications in industry by supporting the integration of the product design, manufacturing, and delivery processes. Currently in use to create models or to produce components or replacement parts, 3D printing will become more important as the range of printable materials expand (often plastics, metals, ceramics, and glass for the time being) and the surface detail and quality of the printed products improve, thus meeting the expectations of end-use markets. Companies will then sell designs instead of physical products. Other applications in the medical field include the bioengineering of implants, prostheses, or organs via DNA printers.

Reaping the benefits these emerging technologies could bring will depend, among other challenges, upon the capacity of labor markets to adapt. As a matter of fact, technological change is one of the major factors likely to influence employment markets, the demand and supply of skills, and the structure of occupations.

Advances in machine learning, robotics, and artificial intelligence will inevitably prompt automation, changing labor demand and driving job displacement [Brynjolfsson, McAfee, 2011]. However, automation will no longer be confined to physical or manual tasks, the dirty, dangerous, or dull tasks, but may put at risk many intellectual, cognitive, or analytical white-collar jobs encompassing some routine tasks, starting with transportation, office support, or consumer services. The OECD estimated that $9 \%$ of jobs in OECD countries could be automated and $25 \%$ could change significantly as a result of the automation of 50\%-70\% of the associated tasks [Arntz et al., 2016].

In turn, other kinds of jobs will appear as new products, processes, or new business models take shape. For instance, the digital transition and big data are spurring demand for data specialists and skills for data analysis that exceeds both the current supply and the current capacity of the education and training systems. Although the occupational structure has already evolved in many countries, with job creation polarizing high- and low-skilled occupation groups and job losses concentrated in middle-skilled routine occupations [Goos et al., 2009; Autor, Dorn, 2013], the areas, scope, and scale of the "creative destruction" to come are still unknown.

Against this backdrop of uncertainty and considering the sizeable repercussions the current technological transformations could have on production systems and societies at large, policy makers need evidence and anticipatory intelligence for forecasting the impact of technological change upon work qualifications and work conditions as well as for the design and evaluation of science, technology, and innovation policies (Seidl da Fonseca in this Special Issue).

New jobs may deviate from the standard full-time employment model and take on non-standard forms (i.e., part-time, temporary, on-call, etc.). Emerging technologies make it possible to de-bundle jobs into smaller tasks in support of global and digital production. The servitisation of the economy has furthermore encouraged the fragmentation of employment into smaller units of self-employment. Work has already become more fragmented with an increasing number of workers holding non-standard jobs or operating a non-standard job as a side business to complement income from their regular work (Bögenhold et al. in this Special Issue).

Yet, non-standard jobs are often associated with low quality jobs, lower wages, and lower skills. While a few may find more work flexibility in the "gig" economy, disadvantaged populations are more likely to be trapped in unconventional work arrangements, and be given less opportunities to access training opportunities and a social safety net (OECD, 2015b).

The rise of the digital platform economy is enabling the reorganization of the labor market and work arrangements [Kenney, Zysman, 2016]. The Internet has increasingly become a space for employees and recruiters to meet. Online work mediation platforms have emerged in recent years linking job seekers and freelancers with companies inviting them to bid on a variety of tasks (Roshchin et al. in this Special Issue) 
New jobs will require new competencies and new skillsets. The mix of skills needed to perform in modern societies has become increasingly complex and will keep evolving as technology-enhanced work environments evolve, requiring future generations of workers to develop digital proficiency and lifelong learning capacities at an early age. For the time being, the tasks that are harder to automate involve problem-solving capabilities, intuition, creativity, and persuasion [Frey, Osborne, 2013]. Soft skills such as self-organization, management, teamwork, or communication skills are also likely to grow in importance in the emerging world. The change in educational profiles will call for a renewed education and training policy agenda and new approaches to teachers' training (Shamsi in this Special Issue). Firms will build their human capital around the new skillsets, also implementing organizational changes and adopting new management practices to ensure an efficient use of their intangible assets (Zavyalova et al in this Special Issue).

Overall, the inequalities and social cleavage that may potentially arise from the emerging technological changes are issues of major concern. Inequalities will not only result from job destruction and employment polarization, but also from weaker social mobility and the persisting digital divide. Job polarization is likely to hit the white-collar middle class hard. Social inequity is also likely to worsen across industries, regions, or occupations as the digital divide between those who can and those who cannot keep up with technological change widens. In that respect, labor prospects for women are unclear [OECD, 2017]. While women are historically less represented in scientific and technological fields, digitalization can help bridge the gender gaps on the labor markets. In particular, the digital platform economy could provide opportunities for greater work flexibility and better work-family balance or for lowering cultural barriers and levelling the playing field with men.

Similarly, the potential dismantlement of the $20^{\text {th }}$ century employment model that rose with mass production and links contracted employment with wages and the welfare system is of particular concern. Employment, pension, healthcare, and social welfare systems are closely intertwined, with salary-based taxes accounting for a substantial share of public resources and budgetary sustainability. Ensuring the resilience, adaptability, and efficiency of labor markets is therefore not only a matter of addressing the skills needed for the Next Production Revolution, but also a prerequisite for social stability and cohesion.

The opinions expressed and arguments employed herein are those of the authors and do not necessarily reflect the official views of the OECD or of the governments of its member countries.

\section{References}

Arntz M., Gregory T., Zierahn U. (2016) The Risk of Automation for Jobs in OECD Countries: A Comparative Analysis (OECD Social, Employment and Migration Working Paper no 189), Paris: OECD. Available at: http:// dx.doi.org/10.1787/5jlz9h56dvq7-en, accessed 26.11.2017.

Autor D.H., Dorn D. (2013) The growth of low-skill service jobs and the polarization of the US labor market. The American Economic Review, vol. 103, no 5, pp. 1553-1597. Available at: http://economics.mit.edu/files/1474, accessed 26.11.2017.

Brynjolfsson E., McAfee A. (2011) Race Against the Machine: How the Digital Revolution is Accelerating Innovation, Driving Productivity and Irreversibly Transforming Employment and the Economy, Lexington, MA: Digital Frontier Press.

Frey C.B., Osborne M.A. (2013) The future of employment: How susceptible are jobs to computerisation?, Oxford, UK: University of Oxford.

Goos M., Manning A., Salomons A. (2009) Job polarization in Europe. American Economic Review: Papers \& Proceedings, vol. 99, no 2, pp. 58-63. Available at: http://dx.doi.org/10.1257/aer.99.2.58, accessed 26.11.2017.

Kenney M., Zysman J. (2016) The Rise of the Platform Economy. Issues in Science and Technology, vol. 32, no 3 (Spring 2016). Available at: http://issues.org/32-3/the-rise-of-the-platform-economy, accessed 26.11.2017.

Keynes J.M. (1930) Economic Possibilities for our Grandchildren. Essays in Persuasion, New York: W.W. Norton \& Co., pp. 358-373. Available at: www.econ.yale.edu/smith/econ116a/keynes1.pdf, accessed 26.11.2017.

OECD (2015a) Data-Driven Innovation: Big Data for Growth and Well-Being, Paris: OECD Publishing. Available at: http://dx.doi.org/10.1787/9789264229358-en, accessed 26.11.2017.

OECD (2015b) Non-standard work, job polarisation and inequality. In It Together: Why Less Inequality Benefits All, Paris: OECD, pp. 135-208. Available at: http://dx.doi.org/10.1787/9789264235120-7-en, accessed 26.11.2017.

OECD (2016) Science, Technology and Innovation Outlook 2016, Paris: OECD, Available at: http://dx.doi.org/10.1787/ sti_in_outlook-2016-end, accessed 26.11.2017.

OECD (2017) Going digital: The future of work for women. The Pursuit of Gender Equality: An Uphill Battle, Paris: OECD, pp. 269-282. Available at: http://dx.doi.org/10.1787/9789264281318-26-en, accessed 26.11.2017. 